\title{
EXPRESSÃO HUMANA NA DANÇA
}

\section{Tainá Stephanie Friggi Oliveira ${ }^{1}$ Lindsay Caroline de Brito Ribeiro²}

Resumo: Este artigo tem como propósito relatar a construção de uma Pesquisa de Campo realizada como parte do trabalho de conclusão de curso. Na primeira etapa foram transmitidos três vídeos que mostram em cada um deles estilos diferentes de dança. Na segunda etapa foi realizada uma pesquisa feita por meio de um formulário com perguntas aos alunos do $5^{\circ}$ ano, posteriormente sistematizadas para análise dos conhecimentos, das reações e sensações diante do que foi transmitido pela dança. O objetivo é mostrar como bailarinos, público e os alunos de ensino fundamental percebem a dança e quais são as emoções envolvidas nesse processo de percepção.

Palavras-chave: Expressão; Emoções; Corpo e dança.

\footnotetext{
1 Universidade do Vale do Paraíba/Faculdade de Educação e Artes. E-mail: nanah18nove@hotmail.com.

2 Universidade do Vale do Paraíba/Faculdade de Educação e Artes. E-mail: lindsaycbr@hotmail.com.
} 